\title{
Strategies to Implement Knowledge Management Systems
}

\author{
MaryJane C. McGee \\ Walden University \\ Minneapolis MN, USA
}

\author{
Ify S. Diala \\ Contributing Faculty \\ Walden University \\ Minneapolis MN, USA
}

\begin{abstract}
More than $38 \%$ of the U.S. public workforce will likely retire by 2030, which may result in a labor shortage. Business leaders may adopt strategies to mitigate knowledge loss within their organizations by capturing knowledge in a knowledge management system (KMS). The purpose of this single case study was to explore strategies that information technology (IT) managers use to develop and implement a KMS. The target population consisted of IT managers in a small-sized organization located in northwestern Florida who had implemented a KMS successfully. The conceptual framework for this study was organizational knowledge creation theory. The collection of public documents, execution of semistructured interviews with 5 qualified participants, literature on the topic, and member checking formed the determination of the findings of the study. Using triangulation and coding the data for emergent themes, 6 themes emerged from the data analysis: (a) training, (b) customer focus, (c) policy and governance, (d) leadership and management support, (e) communication and marketing, and (f) business process management. The application of the findings may contribute to social change by identifying strategies that leaders and IT managers from communities and government agencies use in implementing a KMS that may facilitate transparency and open flow of information to citizens, and allow access to timely, civic, and potentially life-enhancing information.
\end{abstract}

Keywords: knowledge sharing; knowledge management; implementation Strategies; organizational Knowledge; collaboration.

\section{INTRODUCTION}

Effective knowledge management system (KMS) implementation strategies may benefit business leaders as a tool to capture and retain knowledge from departing employees. The lack of strategies to develop and implement a KMS threatens organizational performance, competitive advantage, and bottom-line profits due to knowledge loss from departing employees (Levy, 2011; Massingham, 2014; Massingham \& Massingham, 2014). The need to retain, capture, and share knowledge of departing experienced employees emphasizes how the loss of organizational knowledge can lead to additional reductions in competitive advantage, organizational productivity, and economic growth (Jennex, 2014; Martins \& Meyer, 2012). Researchers have studied KMS implementation failure rate (e.g., Saini, Nigam, \& Misra, 2013); significant returns of adoption of KMS and factors that influence KMS use and acceptance (e.g., Zhang, Gao, \& Ge, 2013); and the effect of implementing a KMS to help retain, transfer, and capture critical knowledge of departing employees (e.g., Joe, Yoong, \& Patel, 2013). As Neumark, Johnson, and Mejia (2013) discovered, 38\% of the U.S. public workforce will likely retire by 2030 . This exodus of experienced workers may result in a labor shortage. Therefore, the reports of knowledge loss show that failure to implement a KMS may cause financial and productivity losses in organizations (Neumark et al., 2013). Business leaders may use the strategies to develop and implement a KMS to strengthen competitiveness in the industry.

\section{PROBLEM \& PURPOSE OF THE STUDY}

In $2017,31 \%$ of 1.96 million federal employees will be eligible to retire, which could result in the loss of organizational knowledge if not adequately captured in a KMS (U.S. Government Accountability Office, 2014). Fifty to ninety percent of organizational knowledge, if not captured in a KMS, creates a knowledge gap, as well as an average annual financial loss of $\$ 1.2$ million for medium-sized enterprises (Martins \& Meyer, 2012; Massingham, 2014). The general business problem that was addressed in this study was the need for a KMS implementation strategy to capture organizational knowledge. The specific business problem that addressed in this study was that some IT managers lack strategies to develop and implement a KMS. The purpose of this qualitative, single case study was to explore strategies that IT managers could use to develop and implement a KMS. The target population was five IT managers in northwestern Florida, United States, whom were selected because they were experienced in implementing a KMS. The data from the study may provide IT managers with strategies to contribute to social change because the implementation of strong information and KMS may empower community leaders to collaborate within an infrastructure for sharing information.

\section{DISCUSSIONS}

\subsection{Knowledge Sharing and Transfer}

Business organizations understand the need to invest in resources Influence, generational diversity, and use of KMS are essential to successful knowledge transfer. Knowledge transfer takes place through discussion among brokers in organizations as a process to formalize knowledge transfer (Conklin, Lusk, Harris, \& Stolee, 2013). Conklin, Lusk, Harris, and Stolee (2013) emphasized that organizations have knowledge brokers-influential leaders who serve as facilitators between knowledge creators and users-to facilitate formal knowledge transfers. Levy (2011) stated that organizations with retiring employees do not risk business loss and competitive advantage if they have a process that engages in transferring and retaining knowledge. Levy (2011) argued that knowledge continuity produced retention through its structured documentation and integration. The capture of lessons learned and best practices, knowledge transfer based on prioritization, and use of enterprise KMS were all benefits of KMS. 
The characteristics of each generation in the workplace influence knowledge transfer methods. Gursoy and Karadag (2013) discovered that managers needed to recognize the importance of differences and its influence in workplace attitudes, interactions, job satisfaction, and productivity. Gursoy and Karadag further noted that managers should capitalize on these differences when implementing organizational change, decreasing tension and conflict, and fostering generational synergy in the workplace. If managers capitalize on these strengths, KM in the context of a multigenerational workplace-especially with a high percentage of eligible retirees - can be useful when facilitating intergenerational knowledge transfer (Gursoy \& Karadag, 2013). Cummings-White and Diala (2013) emphasized the importance of integrating $\mathrm{KM}$ into an organization's processes in combination with culture change to promote knowledge sharing and transfer. Cummings-White and Diala (2013) further noted that capturing, retaining, and leveraging knowledge of older workers would allow younger workers to leverage existing organizational knowledge to foster efficiency and productivity. Business leaders' approaches of using communities of practice may contribute to modifications in the practice of knowledge transfer in businesses with a multigenerational workforce.

Business leaders realized the importance of enabling a KMS concept to encourage managers and employees to participate in knowledge sharing. Sousa and González-Loureiro (2015) noted that the high levels of creativity and innovation at organizational levels were associated with the need of managers and employees to participate and share knowledge. Sousa and González-Loureiro (2015) indicated that knowledge sharing and reuse were difficult for managers due to the availability and use of different mechanisms (such as documents, databases, intranets, KMS, communities of practices, and groupware). The lack of a structured KM strategy in an organization negatively impacted managers' willingness to use shared knowledge.

Although Sousa and González-Loureiro (2015) believed in a standardized capability to allow participation and sharing of knowledge, Baralou and Tsoukas (2015) introduced another concept that captured knowledge from a synchronous and virtual environment. Baralou and Tsoukas (2015) indicated that in addition to face-to-face interactions, workers created and transferred knowledge through information and communication technologies such as synchronous teleconferencing tools (like Skype), collaborative software applications that allow users to create, share, and edit files and electronic mails. Baralou and Tsoukas (2015) believed that knowledge is created simultaneously through a dialogical or conversational basis and virtual communication that is increasingly conducted via ICTs, instant messaging, and a variety of media. Therefore, knowledge transfer through a synchronous and collaboration format is an outcome of knowledge creation.

Wikis are an example of a collaboration tool used for knowledge capture because of the capability to track modifications; such tracking allows individuals to view contributions provided by other team members in a simple manner (Kiniti \& Standing, 2013). Pangil and Chan also noted that a virtual team's effectiveness is associated with the three dimensions of trust: (a) personal-based, (b) institutionalbased, and (c) cognitive-based. This type of tool is widely used by virtual teams. Pangil and Chan (2014) noted that with virtual teams, it is critical to sustain personal-based trust among its members to improve the knowledge sharing practice and create a platform to facilitate institutional-based trust. The influence of trust and knowledge sharing contribute to the effectiveness of virtual teams.

The culture in organizations-mostly government ones-and employees' attitudes towards knowledge sharing are positive when individuals work in hierarchical environment (Buheji, Al-Hasan, Thomas, \& Melle, 2014). Luu (2014) indicated that employees were willing to share knowledge if organizations had a strong culture, ethic, and competitive intelligence. Luu (2014) believed that managers and business leaders should focus on the creation of a dynamic knowledge sharing culture and consider value-added factors as critical influences in the success of KM implementation. The elements discussed in the studies of Buheji, Al-Hasan, Thomas, and Melle (2014), and Luu (2014) are significant factors of culture change or openness. Through culture change, business leaders optimize knowledge transfer and create a pathway to building competitive advantage.

Lee and Lim (2015) reported that KMS is an effective organizational knowledge sharing enabler; its successful implementation impacted the level of utilization concerning knowledge creation, reuse, and dissemination. Lee and Lim (2015) illustrated several aspects of KMS: (a) functions, (b) quality, (c) content, (d) user interface, (e) user satisfaction, and (f) perceived benefits. However, knowledge workers believed that if the KMS was slow, had a weak set of functions and features, and had an inefficient search capability; it could affect users' acceptance and satisfaction (Lee \& Lim, 2015). The functionality and stability of a KMS influence the knowledge workers' acceptance and usage.

Rao, Guo, and Chen (2015) reported results consistent with the findings in Lee and Lim's (2015) studies. Rao et al. (2015) believed KMS enable and facilitate (tacit) knowledge sharing in organizations. The reliability and availability of knowledge and KMS were necessary for timely decisions and actions of managers and employees. Rao et al. (2015) indicated that employees viewed knowledge sharing as a social process where employees shared experiences and learned from each other. This exchange resulted in the accumulation and acquisition of new knowledge to improve employee performance. The influence of knowledge sharing and KMS is critical in the business processes and structure of an organization (Rao, Guo, \& Chen, 2015).

Explicit and tacit knowledge sharing practices facilitate motivation and performance. Hau, Kim, Lee, and Kim (2013) discovered that organizational reward systems could be counterproductive to knowledge transfer endeavors. Hau et al. (2013) noted that organizational rewards have a negative effect on tacit knowledge transfer but a positive effect on explicit knowledge transfer. Employee motivation towards transfer knowledge also affects KM efforts (Evans, 2013). Evans (2013) revealed that a positive correlation between the level of motivation and willingness to share knowledge and knowledge transfer behavior exists. Social affiliation with a group, trust, and rewards are factors individuals consider when they determine their willingness to transfer knowledge (Evans, 2013). Thus, motivation among employees plays a key role in transferring knowledge (Hu \& Randel, 2014).

$\mathrm{Hu}$ and Randel (2014) stated that a positive relationship existed between extrinsic motivation and knowledge sharing. Sankowska (2013) noted strong connections between employee trust and knowledge transfer. Hu and Randel (2013) posited that organizations with a deep-rooted culture of trust have employees who display willingness to share knowledge. 
Business leaders in organizations who illustrated presence of knowledge transfer did so based on the trust that employees had; this trust is directly related to a strong competitive advantage (Sankowska, 2013). Therefore, motivational factors, employee trust, and rewards positively influence knowledge sharing.

In addition to the findings of Hau et al., (2013), Evans (2013), and $\mathrm{Hu}$ and Randel (2014), Wang, Wang, and Liang (2014) reported a different finding that revealed tacit knowledge sharing significantly contributed to all components of intellectual capital-human, structural, and relational capital-while explicit knowledge sharing significantly contributed only to human and structural capital. Additionally, Wang et al. (2014) indicated that human, structural, and relational capital played vital roles in improving the operational and financial performance of businesses. The concept of tacit knowledge sharing consistently produced similar benefits to the financial and operational performance of an organization.

Another way to share knowledge is via discussion forums in virtual communities. Reliable technical infrastructure with discussion forums facilitated communication and enabled knowledge creation and knowledge sharing in virtual communities. Atapattu and Jayakody (2014) suggested that, in addition to a reliable KMS, employee propensities (such as teamwork, incentives, continuous learning, and openness to change) were top determinants of KM success. As such, the practice of teamwork among knowledge workers was a key source of the knowledge-generation process. Consumer participation and interaction in discussion forums contributed to building trust, commitment, and knowledge, and enhanced online relationships (Atapattu \& Jayakody, 2014). Similarly, continuous learning promoted high performance and advancement for workers who were open to such change; these people influenced the success of KM because they were willing to generate new knowledge, to take on new projects, and to work with teams (Atapattu \& Jayakody, 2014). Reliable KMS provide a consistent collection method for collating, storing, and disseminating data that facilitate organizational performance and success of KM initiatives.

Expert employees are vital to organizations. When organizational leaders ignore lack of knowledge transfer among employees, the result may be decreased organizational productivity and output, and loss of competitive advantage (Kim et al., 2013). Knowledge transfer, codification, or sharing are important to business leaders who focus on reducing productivity and competitive advantage loss, especially when expert employees depart the organization, receive promotions, or change positions (Kim et. al., 2013). Therefore, business leaders should recognize that losing employee experience and productivity might result in knowledge loss.

\subsection{Knowledge Management Practices and Knowledge Management Enablers}

Several researchers (Jain \& Joseph, 2013; Oliva, 2014; Ramin, Taib, Hashim, Noordin, \& Yasin, 2013) defined knowledge management (KM) comparably. KM is a structured method focused on creating, sharing, harvesting knowledge, and leveraging it as an organizational asset to improve organizational leaders' abilities to deliver products or services (Ramin et al., 2013). Like Ramin et al. (2013), Jain and Joseph (2013) defined KM as a process used to create, capture, store, exploit, share, and apply knowledge to benefit employees, the organization, and its customers.
Various definitions of KM and its associated practices reveal that KM is an organizational asset. Oliva (2014) claimed that organizations could achieve competitive advantage by having its employees adopt KM practices. KM practices facilitate improvement of business processes. Oliva posited the main barriers to organizational $\mathrm{KM}$ are definition, acquisition, dissemination, storage, application, and evaluation of knowledge. The KM practices are delineated based on (a) alignment with organizational strategy, (b) a cultural focus on innovation, (c) a level of competence achievement, (d) a transparency in the definition of knowledge, and (e) upgraded tools (Oliva, 2014).

Other researchers (Jain \& Joseph. 2013; Oliva, 2014; Ramin et al. 2013) emphasized a competitive advantage for people in organizations who adopt KM practices and value KM practices as a major contributor to their success. Hasanian, Chong, and Gan (2015) stated that specific KM factors showed the highest predictor of success associated with the creation of an effective knowledge-based customer relationship. KM factors such as (a) strategy, (b) management leadership, (c) process, (d) IT, (e) organizational infrastructure, (f) organizational culture, (g) training and education, and (h) performance measurement influence customer knowledge creation and distribution in an organization. This influence, in turn, improves customer satisfaction (Hasanian et al., 2015).

Likewise, Matayong and Mahmood (2013) emphasized that the bases of organizations' successes in the use of KMS are as follows: (a) adoption, (b) diffusion, (c) usage, and (d) implementation. Matayong and Mahmood further related that people in some organizations are deficient in assimilating the KMS; they use it to innovate. As such, investigating the strategies that determine the outcomes of models such as adoption, diffusion, use, and implementation is important to knowledge workers in those organizations. Ultimately, KM enablers and KM practices result in providing customers with organized and correct data- the basis for gathering data and information - and are a reliable channel for generating and sharing knowledge (Jain \& Joseph, 2013; Oliva, 2014; Matayong \& Mahmood; 2013; Ramin et al., 2013).

Several researchers explained how KM practices affect organizational strategic planning and management of knowledge and information (Alegre, Sengupta, \& Lapiedra, 2013; Jayawickrama, Liu, \& Smith, 2014). The purpose of $\mathrm{KM}$ is to aid business leaders in achieving information, knowledge creation, and diffusion (Alegre et al., 2013). The fundamental emphasis of $\mathrm{KM}$ is steering organizational strategic planning so business leaders can recognize the types of knowledge that exist in business processes (Alegre et al., 2013). Knowledge dissemination includes business processes that efficiently integrate tacit and explicit knowledge throughout an entire organization (Alegre et al., 2013). A KMS is a group of systems and procedures that business leaders use to manage, capture, and store knowledge (Alegre et al., 2013). KM is a resource and capability that business leaders can implement to support organizational strategic planning (Jayawickrama et al., 2014). The goal is to ensure that the discovery and documentation of the required knowledge and people involved with new projects (e.g., ERP implementation processes) will incorporate people, products, and services (Jayawickrama et al., 2014). Business leaders adopt $\mathrm{KM}$ practices and KMS as fundamental tools to facilitate KM strategy and knowledge capture.

The need for a KMS to facilitate and create knowledge sharing is an important influence in organizations. 
Kanjanabootra, Corbitt, and Nicholls (2013) suggested that strong KM practices positively affect internal communications (ICs); KM technologies serve as the structural mechanism to leverage KM practices. In addition, positive organizational performance, innovation, and transformation are a stable set of management practices that result from the maximum use of IC assets and KM technologies (Kanjanabootra et al., 2013). Although Kanjanabootra et al. emphasized the maximum use of ICs, Bharati, Zhang, and Chaudhury (2015) believed in the use of social media as a KM enabler. Bharati et al. explained that the emphasis on KM has led to improved knowledge quality in organizations, particularly in the use of social media as a KM enabler. Bharati et al. discovered that three dimensions of social capital are as follows: (a) structural, (b) relational, and (c) cognitive. Each is significantly associated with organizational $\mathrm{KM}$. The use of social media is a positive link between increased interactions among knowledge workers, and it enhances the KM practices in the organization.

Several researchers (Donate \& de Pablo, 2015; Lai, Hsu, Len, Chen, \& Lin, 2014; Martín-de Castro, 2015) explained the relationships between leadership, KM, and innovation through a different lens. The role of leadership in KM initiatives is a key aspect of innovation strategy. Donate and de Pablo (2015) theorized that $\mathrm{KM}$ is critical for the innovation process. In addition to the work done by Donate and de Pablo (2015), Martin-de Castro (2015) expounded on the cross-fertilizing role of three different research constructs: (a) collaborative/open innovation from strategy and innovation management research, (b) absorptive capacity from knowledge-based view, and (c) market orientation from marketing research. As organizational leaders recognized the need to develop, implement, and use KMS, the employees' performance and innovation improve (Kanjanabootra et al., 2013; Massingham, 2014).

Innovation propels organizational leaders to stretch the bounds of limitations and create new strategies using KM processes and KM technologies. Lai, Hsu, Len, Chen, and Lin (2014) found that knowledge creation, knowledge storage, industry cluster resources and relationships, market performance, and product performance were related to the improvement of corporate innovation performance. Lai et al. (2014) indicated that by using industrial clustering, businesses leaders had frequent interaction with employees from downstream and upstream firms; and this increased interaction resulted in better innovation performance. Lai et al. (2014) also noted that the internal and external KM practices facilitated access and acquisition of resources through lower costs and improved relationship among sub organizations.

Business leaders can take the approach of coaching, mentoring, and building trust to help support employees in knowledge sharing before implementing a new system (Liu, 2013; Pangil \& Chan, 2014). The purpose of KM, according to Liu (2013) is to generate innovations and new ideas to respond to the changes in the competitive operating environment. The main benefits of enterprise resource planning (ERP) systems are to help business leaders manage and monitor the flow of information within an organization (Liu, 2013). Although Donate and de Pablo (2015), Liu (2013), and Martin-de Castro (2015) had a similar view on $\mathrm{KM}$ and innovation, Lai et al. (2014) discovered a different approach. Leaders needed to develop external relationships and networks through $\mathrm{KM}$, organization learning, and intellectual capital to succeed in technological innovation. A major strength of the study by Apak and Atay (2014) was the discovery that business leaders did not realize the importance of KM. The concern was for business leaders to realize that if a knowledge-based economic approach had been applied, their chances to prove the new value of knowledge would have helped businesses survive in the global economy. Apak and Atay (2014) further noted that there was a high correlation between innovation capability and KM capacity in small and medium enterprises (SMEs). Finally, Apak and Atay (2014) believed that with the support of artificial intelligence and use of modern technology, a cost-effective customer-driven design and manufacturing process would produce an agile and optimal industrial production for small and medium enterprises. These authors (Apak \& Atay, 2014) theorized that effective KM strategies would improve performance, growth, and innovative activities in SMEs while penetrating the international markets.

Authors (Findikli, Yozgat, \& Rofcanin, 2015; Sykes, Venkatesh, \& Johnson, 2014) revealed different findings affecting the innovation, training, and $\mathrm{KM}$ initiatives found in an organization. Findikli et al. (2015) discovered a strong correlation between exploration and exploitation-some of the human resource practices associated with organizational innovation, and KM capacity. The authors (Findikli et al., 2015) pointed out that training and compensation were closely related to exploration and exploitation; they also emphasized that knowledge sharing and use of KMS were beneficial to employees (Findikli et al., 2015). Sykes, Venkatesh, and Johnson (2014) noted that business leaders should offer training for employees to maximize the benefits and features of the system and should support the learning process during the implementation phase. As such, although KM and innovation were related, knowledge sharing using KMS would also benefit employees.

Monavvarian, Asgari, Akhavan, and Ashena (2013) and Kianto, Ritala, Spender, and Vanhala (2014) showed that KM practices and implementation involved human factors, social capital, and intellectual capital. Monavvarian et al. (2013) suggested that social and human factors were the most important aspect of a successful implementation of KM. Monavvarian et al. (2013) noted that the human-social capital (SC) had the greatest effect on KM because of the strong relationship between individuals and groups in organizations; SC facilitates the development of intellectual capital, and enhances knowledge capture, codification, and sharing. Kianto et al. (2014) posited that strong KM practices have positive effects on intellectual capital (IC); and KM technologies serve as the structural mechanism to leverage these practices. Additionally, Kianto et al. (2014) argued that positive organizational performance resulted from the maximum use of IC assets, innovation, and KM practices. Researchers (e.g., Luu, 2014; Marciniak Amrani, Rowe, \& Adam, 2014; Shehata, 2015) strongly believed that KM practices and KM implementation would not be successful by relying solely on technological factors (hardware and software) because social and intellectual capital, as well as the human side of the KM, are key elements of $\mathrm{KM}$ in the organization.

Several studies (Kalyar \& Rafi, 2013; Sabir \& Kalyar, 2013; $\mathrm{Wu} \&$ Chen, 2014) exist regarding learning cultures, innovation, knowledge transfer, and influence of organizational learning to knowledge creation. The value of organizational learning in a knowledge-based organization plays a major role in creating knowledge. Employees with high job satisfaction are more innovative and participative in learning cultures than employees who are dissatisfied with 
their jobs (Kalyar \& Rafi, 2013). Representatives organizations with strong learning cultures encourage scientific innovation (Kalyar \& Rafi, 2013). Furthermore, opportunities for organizational learning during knowledge transfer may be beneficial to remaining or new employees; and the result of this exchange of knowledge could result in job satisfaction (Sabir \& Kalyar, 2013). Sabir and Kalyar (2013) emphasized how knowledge transfer could influence positive social change because of the increased competitive advantage, higher employee retention, and job satisfaction. Guo, Wang, and Feng (2014) explained that business leaders believe that systems implementation will not succeed without a proper learning environment because the culture of end users can influence its success. Guo et al. (2014) emphasized business leaders should direct the learning of end users for them to appreciate the benefits and the enhancements of ERP systems. An organization's learning culture affects knowledge transfer among individuals. Wu and Chen (2014) indicated that knowledge assets and process capabilities produce organizational outcomes. Wu and Chen (2014) believed organizational leaders should focus efforts on the improvement of business process capabilities and KMenabled performance to achieve a competitive advantage thereby profiting from KM investments. The implementation of KM tools could transform an organization into a learning organization where information sharing is an employee value. Al-Aama (2014) explained that with the implementation of effective KMS, knowledge workers within organizations could create, capture, organize, and share knowledge among employees. Al-Aama (2014) believed that executive members in organizations faced challenges, such as high employee turnover, drastic expansion of digitized information (also known as big data), the need to make quick and accurate decisions, the need to eliminate redundant efforts, and the need for collaboration among employees. Therefore, KMS implementers would need to use a taxonomy composed of numerous KM tools as an enabler to capture knowledge (AlAama, 2014). The use of taxonomy and KM tools facilitated the critical processes of knowledge creation, organization, and sharing (Al-Aama, 2014).

Diffin, Coogan, and Fu (2013) and Saini et al. (2013) found similar revelations regarding the need for a successful KMS. To understand what makes an organization successful, Diffin et al. (2013) explored the selection, implementation, and result of Microsoft SharePoint technology as the framework for organizing and sharing collective knowledge. The SharePoint implementation offered a centralized communication and collaboration system among staff members and served as a documentation management solution (Diffin, Coogan, \& Fu, 2013). Saini et al. (2013) emphasized the importance and need for a deeper understanding of portal implementation because, although portal capabilities provide businesses with benefits, the solution still have a high failure rate. The risk and cost of a failed system implementation is a huge concern for business leaders (Saini et al., 2013). Therefore, it is critical for leaders to understand the success factors involved in its implementation.

Although criticisms existed surrounding the difficulty of KMS implementation, Massingham (2014) and Shehata (2015) argued that the success of KMS implementation was achievable pending certain success factors in the strategy. Massingham (2014) opined that KM organizational change affected the performance of KM implementation in terms of user awareness, leadership direction, purpose, role clarity, and users' resistance to change. The benefits of KMS implementation in organizations improved cash flows generated by investment, input management, acquisition, and employee work quality (Massingham, 2014). Shehata (2015) revealed six elements of KMS that had positive influence on firm performance: (a) knowledge creation, (b) acquisition, (c) codification, (d) diffusion, (e) transfer and, (f) measurement. Shehata (2015) explained that KMS facilitated deployment of essential knowledge processes to improve organizational performance. Nonetheless, KMS are KM enablers that help acquire knowledge, convert it into a useful form, apply or use knowledge created, and reuse it (Shehata, 2015). The introduction of KMS has enabled leaders to facilitate KM sharing throughout organizations.

The implication for managers is to develop and implement KMS successfully to provide organizational leaders with a competitive advantage in the marketplace (Mathrani, Mathrani, \& Viehland, 2013; Sindakis, Depeige, \& Anoyrkati, 2015). Mathrani et al. (2013) believed that enterprise systems and digital business strategy influence the use of data in decision-making processes. Mathrani et al. (2013) also noted that managers based their decisions on knowledge created, operational efficiencies, knowledge captured, and information disseminated within an organization. A successful implementation of enterprise systems resulted in process improvements, data transformation, and financial performance improvements (Mathrani et al., 2013). KMS were valuable to business leaders because they helped strengthen the competitiveness of the leaders in the industry, facilitated innovation, and generated sustainable evolution (Sindakis et al., 2015).

Enterprise systems provide a knowledge and information flow in the areas of supply chain and customer relationship management. Aburub (2015) explained that enterprise systems facilitated performance improvement in terms of cost reduction, information, transparency, and quality, and more efficient business processes. Aburub stated that enterprise systems improved relationships with suppliers, customers, and partners. The use of enterprise systems played a significant role on executives' business agility (Aburub, 2015). Kosalge and Ritz (2015) stated that business leaders who transitioned to an enterprise system managed their accounting, sales, inventory, operations, and improved the supply chain management, inventory or warehouse management, and customer relationship management processes. The transition to enterprise system use resulted in the overall increase in productivity. More importantly, Kosalge and Ritz discovered that business leaders enjoyed the following benefits from post-enterprise system implementation: (a) process improvement and increased process controllability, (b) improved process quality and predictability of business, (c) organizational transparency, (d) integration of activities between departments, (e) improved reporting, (f) discipline in operations, (g) customer/supplier network management, (h) reduction of lead-time, (i) real-time information from products and processes, (j) improved on-time delivery, (k) savings on transaction costs, and (l) improved market responsiveness.

The implementation of KM enterprise systems helps knowledge workers manage the flow of information among multiple entities. Margherita (2014) opined that enterprise systems implemented for business process and information management contributed to the value creation of organizations, and provided greater customer satisfaction, productivity, speed, and a broader organizational view. García-Álvarez (2015) discovered that information and communication technologies (ICTs) influenced KM processes, innovation, and organizational learning within 
organizations. Using the SECI model, García-Álvarez (2015) determined that ICTs captured tacit knowledge and facilitated encoding of the dialogue between employees and customers. This dialogue aided the conversion of knowledge from tacit to explicit, and newly created knowledge became available for sharing (García-Álvarez, 2015). García-Álvarez (2015) further stated that the utilization of ICTs facilitated the creation of a business model through $\mathrm{KM}$ processes, and resulted in innovation and business performance. Reyes, Worthington, and Collins (2015) revealed that top-level managers believed that enterprise KM technologies contributed to agility, adaptability, and alignment within the organization, and improved performance and outcomes of business operations. Technologies, such as enterprise systems and ICTs, provided organizations with real-time access to codified knowledge practices, business processes, and communication, and contributed to management and capture of business operations.

\subsection{Organizational knowledge creation theory}

The organizational knowledge creation theory is focused on knowledge creation through the SECI process. The theory has emerged (Nonaka, 1994) and continues to evolve through the knowledge creation context (Nonaka, Toyama, \& Konno, 2000). In knowledge conversion, a person's experience is expanded through the socialization, externalization, combination, and internalization; it is validated, connected to, and synthesized with the knowledge of other people (Nonaka et al., 2006). Nonaka et al. (2006) identified that the formulation of the organizational knowledge creation theory in the 1990s, evolved owing to the increasing interest in organizational knowledge in academia and the businesses arena. The fundamental concepts from the organizational knowledge creation theory involve promoting leadership, knowledge workers, and systems, and they have become a new model for knowledge creation (Nonaka et al., 2006). The organizational knowledge creation theory applies to my study because its focus was on KM and KMS - the basis of KM activities. The research framework of the study was the foundation that allowed for the development of a KMS implementation. The critical elements and propositions identified in the research were essential to the KM framework based on the observed patterns of people, process, and technology.

Song, Seung, and Uhm (2012) recommended a systematic measurement scale for organizational knowledge creation practices from the SECI model of Nonaka's organizational knowledge creation theory; this scale has five knowledge creation phases: (a) sharing tacit knowledge, (b) creating concepts, (c) justifying concepts, (d) building prototypes, and (e) cross-leveling knowledge. Song et al. discovered that a reliable measure emerges from the analysis of knowledge conversion and creation where organizational knowledge creation practices and other concepts (e.g., learning culture, information systems, and team performance) play a key role. The conversion process emphasizes the use of organizational knowledge creation theory in the capture of information and validates the relationship between the SECI model and knowledge creation theory.

Human interaction, information sharing, and knowledge creation are critical to the success of organizations. Vick, Nagano, and Santos (2013) stated that the organizational knowledge creation theory provides the basis for discussion during the exploitation of tacit and explicit knowledge and conversion of information to knowledge. Vick et al. posited that employees in an organization process information and turn it into knowledge while they use information systems to capture internal business information needs. Although dynamic capabilities theory relates to systems implementation, the integral part of the theory focuses on the effective use of resources and technical capabilities. Similarly, the Bass theory of leadership involves transformation of leadership for achieving organizational performance. The organizational knowledge creation theory was best suited for this study because it focuses on users' knowledge creation and capture using KMS, and facilitates through leadership support.

\section{METHODOLOGY}

This qualitative, single case study involved five IT managers. The sampling method for the study was snowball or chain sampling. Snowball or chain sampling is a strategic process using identified research informants within a select target population to disclose other potential participants for the research study. Data collection processes involved face-toface open-ended questions and semistructured interviews using a semistructured interview protocol to enhance the research technique. Another data collection technique I used to gather participant data included collecting documentation to corroborate data from interviews. A detailed review of documentation helped to discover underlying themes and categories. Documentation such as written policies, standard operating procedures, business rules and best practices manuals, and brochures helped me develop a deeper understanding of the strategies involved in the successful KMS implementation. Methodological triangulation in a case study involves the use of several methods of data collection to promote. For a proper analysis of data, Yin's (2011) fivephase logical and sequential process: a) compiling, (b) disassembling, (c) reasse.mbling, (d) interpreting, and (e) concluding was applied. NVivo 11 qualitative data analysis software was used because it presented numerous functionsincluding querying and theme identification - that were not available via manual analysis. The identification of applicable categories or themes in interviews and document permits researchers to merge evidence

\section{FINDINGS AND RESULTS}

Findings from this study resulted to six main themes from the data collection and analysis:

\section{$i \quad$ Emergent Theme 1: Training}

The findings from this theme includes: All five participants pointed out that user training was the key to their projects' success. Training enabled users to recognize and appreciate system benefits. Participants explained that training should be customized based on the users' abilities and needs, such as awareness and basic and advanced training. employing different training techniques based on the aptitude or technological familiarity of users was essential due to a generational gap.

ii $\quad$ Emergent Theme 2: Customer Focus

The findings from this theme includes: That one of the key strategies used to successfully implement a KMS was to ensure that customers were provided with the appropriate level of training and prompt customer support when needed. Creating, maintaining, and 
building a long-lasting relationship with customers may reduce the risk of user resistance during the KMS implementation. The IT managers affirmed that customer focus and support strengthened the customer relationship during the KMS implementation. The strong customer relationship contributed to the success of the KMS implementation.

iii $\quad$ Emergent Theme 3: Policy and Governance

The findings from this theme includes: All participants believed that without written guidance and procedures, IT managers could not successfully direct the use and acceptance of KMS. The development of manuals as a user guide explained the how-to of the KMS. Policy and governance played a significant role in the KMS implementation because it provided standardization and order to the project.

\section{iv $\quad$ Emergent Theme 4: Leadership and Management Support}

The findings from this theme includes: That leadership support played a significant role when effecting change management. Leadership support facilitated change management, especially when faced with the generational gap and user resistance. When the KMS team briefed senior leaders, the KMS initiative became popular and widely accepted. The IT managers emphasized the importance of leadership and management support in implementing KMS because it showed that when leaders in the organizations facilitate change and lead by example, the users follow.

\section{$\boldsymbol{v} \quad$ Emergent Theme 5: Communication and Marketing}

The findings from this theme includes: The importance of team meetings, marketing, and routine communication with users. Communication, information campaign, and marketing strategies influenced user behavior concerning user acceptance and KMS adoption. Communicating with customers to ensure training and support were provided was important during the initial, mid-term, and final phase of KMS implementation.

vi Emergent Theme 6: Business Process Management

The findings from this theme includes: The importance of integrating and automating business processes during the KMS implementation. The importance of integrating the business processes of an organization while adopting different technologies. Identifying business processes for integration to the KMS helped create the communication strategy. KMS was instrumental in streamlining business process, provided continuity, and contributed to mission effectiveness focusing on and automating users' business processes were keys to the success of KMS implementation.

\section{CONCLUSION}

Creating a viable approach for capturing reusable knowledge is a perpetual problem in organizations. The lack of strategies for implementing a KMS continues to worsen the knowledge loss problem in a workforce that has constant employee turnover. The implementation and use of technologies, such as KMS, impact social, cultural, organizational, technical, and other institutional pressures. Aligning business strategies to develop capabilities have increased in importance as businesses strive for competitive advantage in a diverse and changing marketplace. A solution to this imminent gap in knowledge loss is to take the necessary actions of capturing and retaining operational knowledge of departing employees using a KMS. In addition, management support contributed to the success of a KMS implementation. Also, successful KMS implementation is based on change management strategies embedded in organizational culture change, knowledge transfer, and organizational learning. The implication of this research, consequently, goes beyond the private and public sector and extends to all KMS implementation within local and global communities. Despite the limitations found, this study enhanced business leaders' understandings of strategies used to implement a KMS successfully. Companies lost billions of dollars because of lost knowledge and failed KMS implementation; unless the right strategies for successful implementations are developed and identified, businesses will continue to experience difficulties capturing organizational knowledge. Business leaders must be able to assess adequately the importance of bridging the gap caused by knowledge loss and finding solutions and strategies to capture knowledge. When considering KMS implementation, business leaders should include exploration of key elements of strategies such as appropriate levels of training, customer focus, leadership and management support, policy and governance, communication and marketing, and business process management. The findings may provide new information on strategies used to implement a KMS successfully. In addition, the findings may contribute to organizational development, competitive advantage, and the long-term success of an organization.

\section{REFERENCES}

[1] Levy, M. (2011). Knowledge retention: Minimizing organizational business loss. Journal of Knowledge Management, 15, 582600. doi:10.1108/13673271111151974.

[2] Massingham, P. (2014). An evaluation of knowledge management tools: Part 1 - managing knowledge resources. Journal of Knowledge Management, 18, 1075-1100, doi:10.1108/JKM-11-2013-0449

[3] Massingham, P., \& Massingham, R. (2014). Does knowledge management produce practical outcomes? Journal of Knowledge Management, 18, 221-254. doi:10.1108/JKM-10-2013-0390

[4] Jennex, M. (2014). A proposed method for assessing knowledge loss risk with departing personnel. VINE: The Journal of Information and Knowledge Management Systems, 44, 185-209. doi:10.1108/VINE-07-2012-0028

[5] Martins, E. C., \& Meyer, H. W. J. (2012). Organizational and behavioral factors that influence knowledge retention. Journal of Knowledge Management, 16, 77-96. doi:10.1108/13673271211198954

[6] Saini, S., Nigam, S., \& Misra, S. (2013). Identifying success factors for implementation of ERP at Indian SMEs: A comparative study with Indian large organizations and the global trend. Journal of Modelling in Management, 8, 103-122. doi:10.1108/17465661311312003 
[7] Zhang, S., Gao, P., \& Ge, Z. (2013). Factors impacting end-users' usage of ERP in China. Kybernetes, 42, 1029-1043. doi:10.1108/K-11-2012-0099

[8] Joe, C., Yoong, P., \& Patel, K. (2013). Knowledge loss when older experts leave knowledge-intensive organisations. Journal of Knowledge Management, 17, 913-927. doi:10.1108/JKM-04-2013-0137

[9] Neumark, D., Johnson, H., \& Mejia, M. C. (2013). Future skill shortages in the U.S. economy? Economics of Education Review, 32, 151-167. doi:10.1016/j.econedurev.2012.09.004

[10] U.S. Government Accountability Office. (2014). Federal workforce: Recent trends in federal civilian employment and compensation. Retrieved from http://www.gao.gov

[11] Conklin, J., Lusk, E., Harris, M., \& Stolee, P. (2013). Knowledge brokers in a knowledge network: The case of senior health research transfer network knowledge brokers. Implementation Science, 8, 1-10. doi:10.1186/1748-5908-8-7

[12] Gursoy, D., Chi, C. G., \& Karadag, E. (2013). Generational differences in work values and attitudes among frontline and service contact employees. International Journal of Hospitality Management, 32, 40-48. doi:10.1016/j.ijhm.2012.04.002

[13] Cummings-White, I., \& Diala, I. (2013). Knowledge transfer in a municipality study on baby boomer exodus from the workforce. International Journal of Computer Applications Technology and Research, 2, 367-373. doi:10.7753/ijcatr0203.1029

[14] Sousa, M. J., \& González-Loureiro, M. (2015). Knowledge vision on formalization versus tacitness of sharing knowledge in innovative large organisations. Independent Journal of Management \& Production, 6, 182-202. doi:10.14807/ijmp.v6i1.251

[15] Baralou, E., \& Tsoukas, H. (2015). How is new organizational knowledge created in a virtual context? An ethnographic study. Organization Studies, 36, 593-620. doi:10.1177/0170840614556918

[16] Kiniti, S., \& Standing, C. (2013). Wikis as knowledge management systems: Issues and challenges. Journal of Systems and Information Technology, 15, 189-201. doi:10.1108/13287261311328895

[17] Pangil, F., \& Chan, J. (2014). The mediating effect of knowledge sharing on the relationship between trust and virtual team effectiveness. Journal of Knowledge Management, 18, 92-106. doi:10.1108/JKM-09-2013-0341

[18] Buheji, M., Al-Hasan, S., Thomas, B., \& Melle, D. (2014). The influence of knowledge management on learning in government organisations. American Journal of Industrial and Business Management, 4, 657-670. doi:10.4236/ajibm.2014.411071

[19] Luu, T. (2014). Knowledge sharing and competitive intelligence. Marketing Intelligence \& Planning, 32, 269-292. doi:10.1108/MIP-05-2013-0077

[20] Lee, S., \& Lim, T. (2015). A study on the perception of POKM as the organizational knowledge sharing enabler. VINE, 45, 292318. doi:10.1108/VINE-09-2013-0052

[21] Rao, Y., Guo, K., \& Chen, Y. (2015). Information systems maturity, knowledge sharing, and firm performance. International Journal of Accounting \& Information Management, 23, 106-127. doi:10.1108/IJAIM-11-2013-0060

[22] Hau, Y. S., Kim, B., Lee, H., \& Kim, Y. G. (2013). The effects of individual motivations and social capital on employees' tacit and explicit knowledge sharing intentions. International Journal of Information Management, 33, 356-366. doi:10.1016/j.ijinfomgt.2012.10.009

[23] Evans, M. (2013). Is trust the most important human factor influencing knowledge sharing in organisations? Journal of Information \& Knowledge Management, 12, 1-17. doi:10.1142/S021964921350038X

[24] Hu, L., \& Randel, A. E. (2014). Knowledge sharing in teams social, capital, extrinsic incentives, and team innovation. Group \& Organization Management, 39, 213-243. doi.org/10.1177/1059601114520969

[25] Sankowska, A. (2013). Relationships between organizational trust, knowledge transfer, knowledge creation, and firm's innovativeness. The Learning Organization, 20, 85-100. doi:10.1108/09696471311288546

[26] Wang, Z., Wang, N., \& Liang, H. (2014). Knowledge sharing, intellectual capital and firm performance. Management Decision, 52, 230-258. doi:10.1108/MD-02-2013-0064

[27] Atapattu, A., \& Jayakody, J. (2014). The interaction effect of organizational practices and employee values on knowledge management (KM) success. Journal of Knowledge Management, 18, 307-328. doi:10.1108/JKM-07-2013-0276

[28] Kim, T. T., Lee, G., Paek, S., \& Lee, S. (2013). Social capital, knowledge sharing and organizational performance: What structural relationship do they have in hotels? International Journal of Contemporary Hospitality Management, 25, 683-704. doi:10.1108/IJCHM-Jan-2012-0010

[29] Jain, P., \& Joseph, B. (2013). Knowledge management portals as enablers for institutional competitiveness. VINE: The Journal of Information and Knowledge Management Systems, 43, 400-423. doi:10.1108/VINE-02-2013-0003

[30] Oliva, F. (2014). Knowledge management barriers, practices and maturity model. Journal of Knowledge Management, 18, 10531074. doi:10.1108/JKM-03-2014-0080

[31] Ramin, N. A., Taib, K. M., Hashim, D. M., Noordin, S.A., \& Yasin, S. M. (2013). Knowledge management implementation in a government research institute in Selangor, Malaysia. IBIMA Communications, 2013, 1-12.

[32] Hasanian, G., Chong, C., \& Gan, G. (2015). Application of knowledge management factors on customer relationship management process. Library Review, 64, 583-596. doi:10.1108/LR-10-2014-0111

[33] Matayong, S., \& Mahmood, A. K. (2013). The review of approaches to knowledge management system studies. Journal of Knowledge Management, 17, 472-490. doi:10.1108/JKM-10-2012-0316 
[34] Alegre, J., Sengupta, K., \& Lapiedra, R. (2013). Knowledge management and innovation performance in a high-tech SMEs industry. International Small Business Journal, 31, 454-470. doi:10.1177/0266242611417472

[35] Jayawickrama, U., Liu, S., \& Smith, M. H. (2014). An ERP knowledge transfer framework for strategic decisions in knowledge management in organizations. International Journal of Innovation, Management and Technology, 5, 301-308. doi:10.7763/IJIMT.2014.V5.530

[36] Kanjanabootra, S., Corbitt, B., \& Nicholls, M. (2013). Evaluating knowledge management systems efficacy and effectiveness in a design science context. Journal of Systems and Information Technology, 15, 324-346. doi:10.1108/JSIT-08-2013-0041

[37] Bharati, P., Zhang, W., \& Chaudhury, A. (2015). Better knowledge with social media? Exploring the roles of social capital and organizational knowledge management. Journal of Knowledge Management, 19, 456-475. doi:10.1108/JKM-11-2014-0467

[38] Donate, M. J., \& de Pablo, J. D. S. (2015). The role of knowledge-oriented leadership in knowledge management practices and innovation. Journal of Business Research, 68, 360-370. doi:10.1016/j.jbusres.2014.06.022

[39] Lai, Y., Hsu, M., Len, F., Chen, Y., \& Lin, Y. (2014). The effects of industry cluster knowledge management on innovation performance. Journal of Business Research, 67, 734-739. doi:10.1016/j.jbusres.2013.11.036

[40] Martín-de Castro, G. (2015). Knowledge management and innovation in knowledge-based and high-tech industrial markets: The role of openness and absorptive capacity. Industrial Marketing Management, 47, 143-146. doi:10.1016/j.indmarman.2015.02.032

[41] Liu, Y. (2013). Sustainable competitive advantage in turbulent business environments. International Journal of Production Research, 51, 2821-2841. doi:10.1080/00207543.2012.720392

[42] Apak, S., \& Atay, E. (2014). Global innovation and knowledge management practice in small and medium enterprises (SMEs) in Turkey and the Balkans. Procedia - Social and Behavioral Sciences, 150, 1260-1266. doi:10.1016/j.sbspro.2014.09.142

[43] Findikli, M., Yozgat, U., \& Rofcanin, Y. (2015). Examining organizational innovation and knowledge management capacity. Procedia - Social and Behavioral Sciences, 181, 377-387. doi:10.1016/j.sbspro.2015.04.900

[44] Sykes, T., Venkatesh, V., \& Johnson, J. L. (2014). Enterprise system implementation and employee job performance: Understanding the role of advice networks. MIS Quarterly, 38, 51-72. Retrieved from http://misq.org

[45] Monavvarian, A., Asgari, N., Akhavan, P., \& Ashena, M. (2013). Developing social capital for facilitating knowledge management practices. International Journal of Social Economics, 40, 826-844. doi:10.1108/IJSE-07-2012-0121

[46] Kianto, A., Ritala, P., Spender, J., \& Vanhala, M. (2014). The interaction of intellectual capital assets and knowledge management practices in organizational value creation. Journal of Intellectual Capital, 15, 362-375. doi:10.1108/JIC-05-20140059

[47] Marciniak, R., El Amrani, R., Rowe, F., \& Adam, F. (2014). Does ERP integration foster cross-functional awareness? Challenging conventional wisdom for SMEs and large French firms. Business Process Management Journal, 20, 865-886. doi:10.1108/BPMJ-05-2013-0056

[48] Shehata, G. (2015). Leveraging organizational performance via knowledge management systems platforms in emerging economies: Evidence from the Egyptian information and communication technology (ICT) industry. VINE, 45, 239-278. doi:10.1108/VINE-06-2014-0045

[49] Kalyar, M. N., \& Rafi, N. (2013). 'Organizational learning culture': An ingenious device for promoting firm's innovativeness. Service Industries Journal, 33, 1135-1147. doi:10.1080/02642069.2012.716828

[50] Sabir, H. M., \& Kalyar, M. N. (2013). Firm's innovativeness and employee job satisfaction: The role of organizational learning culture. Interdisciplinary Journal of Contemporary Research in Business, 4, 670-686. Retrieved from http://www.ijcrb.com

[51] Guo, Y., Wang, C., \& Feng, Y. (2014). The moderating effect of organizational learning culture on individual motivation and ERP system assimilation at individual level. Journal of Software, 9, 365-373. doi:10.4304/jsw.9.2.365-373

[52] Wu, I. L., \& Chen, J. L. (2014). Knowledge management driven firm performance: The roles of business process capabilities and organizational learning. Journal of Knowledge Management, 18, 1141-1164. doi:10.1108/JKM-05-2014-0192

[53] Al-Aama, A. (2014). Technology knowledge management (TKM) taxonomy. VINE: The Journal of Information and Knowledge Management Systems, 44, 2-21. doi:10.1108/VINE-12-2012-0052

[54] Diffin, J., Coogan, J., \& Fu, L. (2013). Library systems documentation: Pulling it together with SharePoint. New Library World, 114, 384-397. doi:10.1108/NLW-03-2013-0021

[55] Mathrani, S., Mathrani, A., \& Viehland, D. (2013). Using enterprise systems to realize digital business strategies. Journal of Enterprise Information Management, 26, 363-386. doi:10.1108/JEIM-01-2012-0003

[56] Sindakis, S., Depeige, A., \& Anoyrkati, E. (2015). Customer-centered knowledge management: Challenges and implications for knowledge-based innovation in the public transport sector. Journal of Knowledge Management, 19, 559-578, doi:10.1108/JKM02-2015-0046

[57] Aburub, F. (2015). Impact of ERP systems usage on organizational agility. Information Technology \& People, $28,570-588$. doi:10.1108/ITP-06-2014-0124

[58] Kosalge, P., \& Ritz, E. (2015). Finding the tipping point for a CEO to say yes to an ERP: A case study. Journal of Enterprise Information Management, 28, 1-38. doi:10.1108/JEIM-07-2014-0073

[59] Margherita, A. (2014). Business process management system and activities. Business Process Management Journal, $20,642-662$. doi:10.1108/BPMJ-04-2013-0050 
International Journal of Computer Applications Technology and Research

Volume 6-Issue 10, 441-450, 2017, ISSN:-2319-8656

[60] García-Álvarez, M. (2015). Analysis of the effects of ICTs in knowledge management and innovation: The case of Zara Group. Computers in Human Behavior, 51, 994-1002. doi:10.1016/j.chb.2014.10.007

[61] Reyes, P., Worthington, W., \& Collins, J. (2015). Knowledge management enterprise and RFID systems. Management Research Review, 38, 44-66. doi:10.1108/MRR-01-2013-0011

[62] Nonaka, I. (1994). A dynamic theory of organizational knowledge creation. Organization Science, 5, 14-37. doi:10.1287/orsc.5.1.14

[63] Nonaka, I., Toyama, R., \& Konno, N. (2000). SECI, ßà and leadership: A unified model of dynamic knowledge creation. Long Range Planning, 33, 1-31. doi:10.1016/S0024-6301(99)00115-6

[64] Nonaka, I., von Frogh, G., \& Voelpel, S. (2006). Organizational knowledge creation theory: Evolutionary paths and future advances. Organization Studies, 27, 1179-1208. doi:10.1177/0170840606066312

[65] Song, J., Seung, S., \& Uhm, D. (2012). Systematic and practical measurement of organizational knowledge creation: Developing and validating the knowledge creation practice inventory. Leadership \& Organization Development Journal, 33, 616-631. doi:10.1108/01437731211265214

[66] Vick, T. E., Nagano, M. S., \& Santos, F.C.A. (2013). Identifying the information management process and knowledge creation in technology-based companies: A Brazilian comparative case study. Knowledge Management Research \& Practice, 11, $278-287$. doi:10.1057/kmrp.2012.8

[67] Yin, R. K. (2011). Qualitative research from start to finish (3rd ed.). Thousand Oaks, CA: SAGE Publications. 